\title{
Improvement of Pulmonary Functions Following Septoplasty: How Are Lower Airways Affected?
}

\author{
Arzu Tuzuner ${ }^{1} \cdot$ Gulden Bilgin $^{2}$ - Sule Demirci ${ }^{1} \cdot$ Gulbahar Darilmaz Yuce $^{3} \cdot$ Cemile Acikgoz $^{1} \cdot$ Ethem Erdal Samim $^{1}$ \\ Departments of ${ }^{1}$ Otorhinolaryngology-Head and Neck Surgery and ${ }^{2}$ Pulmonology, Ministry of Health, Ankara Training and Research Hospital, \\ Ankara; ${ }^{3}$ Department of Pulmonology, Ministry of Health, Dişkapi Yildirim Beyazit Training and Research Hospital, Ankara, Turkey
}

Objectives. Nasal septal deviation is a frequent cause of increased nasal airway resistance. A narrow nasal airway would result in a decreased airflow into the lungs. The aim of the present study was to evaluate the alterations of the pulmonary functions following septoplasty using spirometry and 6 minutes walking test (6mWT). And reveal the correlation of symptom score improvement with nasal obstruction symptom score (NOSE) and sino-nasal outcome test (SNOT22) questionnaires following surgery.

Methods. Thirty patients with obvious nasal septal deviations were enrolled in the study. All patients had a detailed otorhinolaryngologic examination, filled NOSE/SNOT22 questionnaires, performed spirometry and 6mWT preoperatively. One month after surgery, NOSE/SNOT22 questionnaires filled by subjects and spirometry with $6 \mathrm{mWT}$ were performed again, and the results were compared.

Results. The mean total walking distance was $702.3 \pm 68.2 \mathrm{~m}$ preoperatively, and it improved to $753.2 \pm 72.6 \mathrm{~m}$ postoperatively $(P<0.001)$. Total tour count increased from 11 (range, 10.8 to 12.0$)$ to 12 (range, 11 to 13.3), and the difference was found statistically significant $(P<0.001)$. When the preoperative and postoperative mean $6 \mathrm{mWT}$ results were compared, diastolic blood pressure increased from 70 to $80 \mathrm{mmHg}(P=0.031)$, heart rate increased from $83.5 \pm$ 13.2 to $90.1 \pm 12.5 \mathrm{bpm}(P=0.017)$, dyspnea rate decreased from 1 to $0(P=0.002)$, and fatigue scores reduced from 2 to $1\left(P=0.003\right.$ ). Evaluation on spirometry findings revealed that $\mathrm{FIF}_{50 \%}$ (maximum inspiratory flow at $50 \%$ of forced vital capacity [FVC]) scores and peak expiratory flow (PEF) values improved significantly after surgery. Septoplasty improves the nasal breathing pattern. While reducing $\mathrm{FEF}_{50 \%}$ (maximum expiratory flow at $50 \%$ of $\mathrm{FVC}$ )/ $\mathrm{FIF}_{50 \%}$, it increases PEF and $\mathrm{FIF}_{50 \%}$ values. In addition, as shown by $6 \mathrm{mWT}$, exercise capacity improves following surgery. Postoperative NOSE and SNOT22 scores reduced markedly compared to preoperative values $(P<0.001)$.

Conclusion. These findings suggest that nasal septal surgery has a positive effect on pulmonary functions, and this can be an important clue for the relationship of lung disorders and nasal obstruction.

Keywords. Nasal Obstruction; Spirometry; Questionnaires; Exercise Test

\section{INTRODUCTION}

Nasal septal deviation is the most common nasal pathology, and

- Received December 15, 2014

Revised March 10, 2015

Accepted March 13, 2015

- Corresponding author: Arzu Tuzuner

Department of Otorhinolaryngology-Head and Neck Surgery, Ministry of Health, Ankara Training and Research Hospital, Kizilcasar Mh. 1233. Sk.

Ankaville sitesi No.27/3 Golbasi,Ankara,Turkey

Tel: +90-312-595-3556, Fax: +90-312-508-3166

E-mail: arzualanya@yahoo.com surgical correction of the nasal deformity results in alterations in the upper and the lower airways. Objective results of septoplasty can be quite variable among patients and for standardization of postoperative outcomes some questionnaires are used in the literature. For subjective evaluation of septoplasty outcome measurement nasal obstruction symptom score (NOSE) and sino-nasal outcome test (SNOT22) forms give highly predictive values [1-3]. Subjective evaluation of upper airway is usually performed with rhinomanometry and acoustic rhinometry, which are used by investigators as well. However the effect of septoplasty, an operation that resolves upper airway obstruction (UAO), on the

Copyright (C) 2016 by Korean Society of Otorhinolaryngology-Head and Neck Surgery.

This is an open-access article distributed under the terms of the Creative Commons Attribution Non-Commercial License (http://creativecommons.org/licenses/by-nc/4.0)

which permits unrestricted non-commercial use, distribution, and reproduction in any medium, provided the original work is properly cited. 
pulmonary system has not been investigated exclusively.

Spirometry and 6 minutes walking test $(6 \mathrm{mWT})$ give important information for pulmonary obstruction, however they are applied to the patients through the upper airways. They are cheap, easy, safe, and well-tolerated tests, and special equipment is not required for them [4].

The aim of this study was to analyze the lower airway improvement and exercise capacity after septoplasty by using subjective and objective measures, namely spirometry and $6 \mathrm{mWT}$, following surgery, and also to observe the correlation of subjective nasal airway function improvement by NOSE (Table 1) and SNOT22 questionnaires.

\section{MATERIALS AND METHODS}

This study was conducted in accordance with the Declaration of Helsinki. Thirty patients with the complaint of chronic nasal obstruction and diagnosed with isolated nasal septal deviation were included in the study.

Patients with hypertension, coronary artery disease, diabetes mellitus, cerebrovascular infarcts, and other nasal pathologies such as allergic rhinitis, excessive turbinate hypertrophy, concha bullosa, chronic rhino sinusitis or nasal polyposis, also cigarette smokers were excluded from study. In addition, the cases that could not cooperate for the $6 \mathrm{mWT}$ and spirometry were excluded from the study.

Anterior rhinoscopy and flexible fiberoptic nasopharyngoscopy revealed a markedly deviated nasal septum in all patients. Consequently, septoplasty was performed under local anesthesia using a hemi transfixion incision, in all patients. We also performed a 6mWT before and 1 month after nasal surgery. For $6 \mathrm{mWT}$, the subjects were encouraged to walk with their best tempo on a flat, 30-m long indoor walking area at the room temperature for 6 minutes. When necessary, the participants were told to take one or more rest breaks. The same physician observed all patients during their walk, and the subjects were informed and positive feedbacks were given for keeping their walking speed, with 1-minute intervals. The physiological parameters such as blood pressure, heart rate and saturation of peripheral oxygen $\left(\mathrm{SPO}_{2}\right)$ were measured before and after walking. The walking distance was calculated after the test. Borg scale was used to evaluate dyspnea and fatigue. Preoperative and postoperative results were compared statistically.

Spirometry was performed 1 day prior to surgery, and 1 month after the surgery (Vmax encore 229C, Carefusion, Yorba Linda, CA, USA) in all patients, while the patient was sitting in an up-right position. Three maneuvers were obtained from each patient during the test, and the best results were recorded by the investigator.

Preoperative and postoperative forced vital capacity (FVC), forced expiratory volume in 1 second $\left(\mathrm{FEV}_{1}\right), \mathrm{FEV}_{1} / \mathrm{FVC}$ ratio,
Table 1. The patients' characteristics regarding their ages and sexes

\begin{tabular}{lr}
\hline Characteristic & \multicolumn{1}{c}{ Value } \\
\hline Age $(\mathrm{yr})$, mean \pm SD (range) & $33.4 \pm 10.9(17-59)$ \\
Sex, $n(\%)$ & $22(73.3)$ \\
Men & $8(26.7)$ \\
Women & \\
\hline
\end{tabular}

peak expiratory flow (PEF), forced expiratory flow at $50 \%$ of FVC $\left(\mathrm{FEF}_{50 \%}\right)$, forced inspiratory flow at $50 \%$ of $\mathrm{FVC}\left(\mathrm{FIF}_{50 \%}\right)$, and the ratio of maximum expiratory to inspiratory flow at $50 \%$ of FVC $\left(\mathrm{FEF}_{50 \%} / \mathrm{FIF}_{50 \%}\right)$ were compared.

The statistical analyses were performed with IBM SPSS Statistics ver. 21.0 (IBM Co., Armonk, NY, USA). The numerical variables were presented as mean \pm standard deviation and median (range), and the categorical variables were presented as the number and the percent. The parametric test hypotheses were controlled before the groups were compared for the numerical variables. $T$-test was used for "before and after" measurements of numerical variables whenever the parametric test hypotheses were satisfied. Wilcoxon test was used when the parametric test hypotheses were not satisfied. McNemar test was used for the comparisons of "before and after" values of the categorical variables. The confidence level was set at $P<0.05$.

\section{RESULTS}

There were 30 patients who met the inclusion criteria (22 men and 8 women), with a mean age of $33.4 \pm 10.9$ (standard deviation) years (range, 17 to 59 years).

Preoperative and postoperative $6 \mathrm{mWT}$ parameters were documented and compared in Table 2. Regarding these findings, the mean total walking distance was $702.3 \pm 68.2 \mathrm{~m}$ preoperatively, and it improved to $753.2 \pm 72.6 \mathrm{~m}$ postoperatively, the difference being statistically significant $(P<0.001)$. Furthermore, total tour count increased from 11 (range, 10.8 to 12.0 ) to 12 (range, 11 to 13.3), and this difference was also found as statistically significant $(P<0.001)$. When the mean preoperative and postoperative $6 \mathrm{mWT}$ parameters were compared, it was found that diastolic blood pressure increased from 70 to $80 \mathrm{mmHg}(P=$ 0.031 ), heart rate increased from $83.5 \pm 13.2$ to $90.1 \pm 12.5 \mathrm{bpm}$ $(P=0.017)$, dyspnea rate decreased from 1 to $0(P=0.002)$, and fatigue scores reduced from 2 to $1(P=0.003)$. These results were found as statistically significant. Systolic blood pressure and $\mathrm{SPO}_{2}$ results did not change statistically following surgery.

The analysis of the spirometry findings revealed that $\mathrm{FEV}_{1}$, FVC, $\mathrm{FEV}_{1} / \mathrm{FVC}$ ratio, forced expiratory flow $25 \%-75 \%$ $\left(\mathrm{FEF}_{25 \%-75 \%}\right.$ ) and $\mathrm{FEF}_{50 \%}$ values did not change statistically when preoperative and postoperative values were compared. On the other hand, $\mathrm{FIF}_{50} \%$ was $3.0 \pm 1.1$ before surgery and $4.6 \pm 1.2$ following surgery. $\mathrm{FIF}_{50 \%}$ scores were statistically significantly higher after septoplasty $(P<0.001)$. 
Table 2. The analyses of preoperative and postoperative and 6 minutes walking test parameters

\begin{tabular}{lccr}
\hline Parameter & Preoperative & Postoperative & P-value \\
\hline SBP $(\mathrm{mmHg})$ & $120(110-130)$ & $120(110-120)$ & 0.157 \\
DBP $(\mathrm{mmHg})$ & $70(70-80)$ & $80(80-80)$ & 0.031 \\
Total tour count & $11(10.8-12.0)$ & $12(11-13.3)$ & $<0.001$ \\
Heart rate $(\mathrm{bpm})$ & & & \\
$\quad$ Before & $83.5 \pm 13.2$ & $90.1 \pm 12.5$ & 0.017 \\
$\quad$ After & $111.2 \pm 21.5$ & $105.4 \pm 17.8$ & 0.169 \\
Dyspnea rate & & & \\
$\quad$ Before & $0(0-1)$ & $0(0-0)$ & 0.002 \\
$\quad$ After & $1.5(1-2)$ & $0(0-1)$ & $<0.001$ \\
Fatigue score & & & \\
$\quad$ Before & $0(0-1)$ & $0(0-0)$ & 0.035 \\
$\quad$ After & $2(1-2)$ & $1(0-1)$ & 0.003 \\
SPO $(\%)$ & & & \\
Before & $98(97-98)$ & $98(97-98)$ & 0.807 \\
$\quad$ After & $98(97-98)$ & $98(97-98)$ & 0.726 \\
Total distance $(m)$ & $702.3 \pm 68.2$ & $753.2 \pm 72.6$ & $<0.001$ \\
ESS $(\%)$ & 26.7 & 23.3 & $>0.999$ \\
\hline
\end{tabular}

Values are presented as median (range) or mean \pm standard deviation. $\mathrm{SBP}$, systolic blood pressure; DBP, diastolic blood pressure; $\mathrm{SPO}_{2}$, saturation of peripheral oxygen; ESS, evaluaiton of symptom scores following exercise.

PEF values improved from $6.6 \pm 1.6$ to $7.6 \pm 1.9$ after septoplasty, and the difference was statistically significant $(P<0.001)$ (Table 3).

Preoperative and postoperative comparison of NOSE scores of patients are found statistically significant $(P<0,001)$. SNOT22 scores are significantly reduced following septoplasty as well $(P<0.001)$ (Table 4).

Correlation results of NOSE-SNOT scores between 6mWT parameters did not find statistically significant in any values. There were no statistically significant correlation between NOSE scores and spirometry findings. However in SNOT scores and spirometry parameters comparison $\mathrm{FEV}_{1}$ variation $(P=0.008)$ on preoperative and postoperative period was statistically significant.

\section{DISCUSSION}

Spirometry is a standard and relatively cheap test in the diagnosis and follow-up of asthma and other respiratory diseases. It has been also used to determine the UAOs. Nasal cavity constitutes an important part of the upper airways. Nasal septal deviation is one of the most frequent abnormalities causing nasal obstruction, and it is a cause of extra thoracic obstruction [5].

The location of the airway obstruction, namely intra- or extrathoracic, determines its effects on the inspiratory and expiratory airflow [6]. When there is an obstruction in the intrathoracic airways, the degree of the obstruction changes with thoracic pressure alterations. The diameter of the airways change due to alterations (increase or decrease) of the thoracic pressure. Pleural
Table 3. Comparison of spirometry parameters before and after septoplasty

\begin{tabular}{lccr}
\hline Parameter & Preoperative & Postoperative & P-value \\
\hline FEV 1 & $3.45(2.83-3.78)$ & $3.49(3.10-3.83)$ & 0.428 \\
FVC & $4.09(3.46-4.62)$ & $4.13(3.25-4.55)$ & 0.191 \\
FEV $_{1} /$ FVC & $83.7 \pm 5.1$ & $83.1 \pm 5.0$ & 0.441 \\
PEF & $6.6 \pm 1.6$ & $7.6 \pm 1.9$ & $<0.001$ \\
FEF $_{25 \%-75 \%}$ & $3.7 \pm 1.2$ & $3.7 \pm 1.1$ & 0.786 \\
FEF $_{50 \%}$ & $4.2 \pm 1.2$ & $4.1 \pm 1.2$ & 0.741 \\
FIF $_{50 \%}$ & $3.0 \pm 1.1$ & $4.6 \pm 1.2$ & $<0.001$ \\
\hline
\end{tabular}

Values are presented as median (range) or mean \pm standard deviation. $\mathrm{FEV}_{1}$, forced expiratory volume in 1 second; FVC, Forced vital capacity;

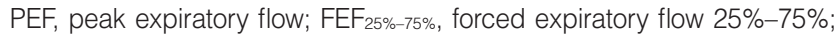
$\mathrm{FEF}_{50 \%}$, maximum expiratory flow at $50 \%$ of $\mathrm{FVC}$; $\mathrm{FIF}_{50 \%}$, maximum inspiratory flow at $50 \%$ of FVC.

Table 4. NOSE and SNOT score variations between preoperative and postoperative period

\begin{tabular}{lccc}
\hline Variable & Pre & Post & $P$-value \\
\hline NOSE & $14(10.8-16.0)$ & $4(0.8-6.3)$ & $<0.001$ \\
SNOT & $57.3 \pm 16.1$ & $39.5 \pm 16.1$ & $<0.001$ \\
\hline
\end{tabular}

Values are presented as median (range) or mean \pm standard deviation.

NOSE, nasal obstruction symptom score; SNOT, sino-nasal outcome test.

pressure surrounds the intrathoracic airways. On the other hand, atmospheric pressure affects the extrathoracic airways. In the case of an extrathoracic airway obstruction, intrathoracic pressure alterations do not affect the diameter of the airways, however the airflow may change in relation with the characteristics of the obstructing lesion. The obstructions in the large airways increase respiratory work regardless of the anatomic location of the obstruction [7]. Vocal cord dysfunction may cause UAO. The vocal cords open during inspiration. When an injury occurs, they remain at the median position, and the airway narrows. The airflow rate decreases during inspiration. Although sometimes expiratory flow rate decreases, mainly inspiratory flow is affected.

It was shown that that preoperative pulmonary function test (PFT) parameters were important for postoperative complications, particularly after abdominal surgery [8]. However, spirometry is also important for determination of the UAOs. PFT alone is not sufficient for postoperative assessment [9]. There are some conflicting reports in the literature about UAO and its relationship with pulmonary function improvement. Also in spirometry extrathoracic and intrathoracic parameters are different from each other [10]. Four values have usually been distinguished in patients with UAO (extraobstruction): (1) $\mathrm{FIF}_{50 \%}$ less than or equal to $100 \mathrm{~L} / \mathrm{min}$; (2) $\mathrm{FEF}_{50 \%} / \mathrm{FIF}_{50 \%}$ greater than or equal to 1; (3) ratio of $\mathrm{FEV}_{1}$ measured in $\mathrm{mL}$ to the PEF rate in $\mathrm{L} / \mathrm{min}$ greater than or equal to $10 \mathrm{~mL} / \mathrm{L} / \mathrm{min}$; and (4) ratio of the $\mathrm{FEV}_{1}$ to the forced expired volume in 0.5 second greater than or equal to 1.5. The last ratio can be determined with a simple spirometer [11].

As reported by Morinaga et al. [12], nasal surgery tends to de- 
crease apnea hypopnea index with significant improvements in the nocturnal oxygenation. Dogan et al. [13] used septal sutures after septoplasty, and did not find any significant differences between the preoperative and postoperative PFT parameters after septoplasty in the early postoperative period. Karaman et al. [5] performed septoplasty in 40 patients, and compared the spirometry parameters obtained before operation and three months after the surgery. They showed that mean FVC (L), $\mathrm{FEV}_{1}(\mathrm{~L}), \mathrm{FEV}_{1}$ / FVC, PEF (L/sec), $\mathrm{FEF}_{25 \%-75 \%}(\mathrm{~L} / \mathrm{sec}), \mathrm{FEF}_{50 \%}\left(\mathrm{~L} / \mathrm{sec}\right.$ ), and $\mathrm{FEF}_{75 \%}$ $\left(\mathrm{L} / \mathrm{sec}\right.$ ) increased statistically significantly, and $\mathrm{FEF}_{25 \%}$ (L/sec) significantly decreased following surgery.

When it is remembered that nasal airway forms $50 \%$ of total airway resistance, it seems worthy to study the alterations of the nasal airflow parameters during exercise and during inspiration, following nasal surgery. Niedzielska et al. [14] studied PFT differences in children after adenoidectomy, and found significant differences for vital capacity, $\mathrm{FEV}_{1}, \mathrm{FVC}, \mathrm{PEF}, \mathrm{FEV}_{1} / \mathrm{PEF}$, and $\mathrm{FEV}_{1} / \mathrm{FVC}$. The authors concluded that resolving the nasal obstruction with adenoidectomy improved PFT parameters in the postoperative period.

In the present study, $\mathrm{PEF}$ and $\mathrm{FIF}_{50 \%}$ values changed statistically significantly 1 month after septoplasty $(P<0.001)$. This improvement suggests that following surgical correction of nasal breathing pattern, respiratory capacity and the deepness of the respiration increase when compared to the preoperative period. On the other hand, the pre- and postoperative differences for $\mathrm{FEV}_{1}, \mathrm{FVC}, \mathrm{FEV}_{1} /$ FVC, $\mathrm{FEF}_{25 \%-75 \%}$, and $\mathrm{FEF}_{50 \%}$ were not statistically significant. But also $\mathrm{FEV}_{1}$ improvement following surgery was statistically significantly correlated with SNOT score difference.

$6 \mathrm{mWT}$ is a good tool for standardization of physical activity with different treatments that are able to change oxygenation, airflow disturbances, oxidative distress regulation and muscle activity improvement [15-17]. 6mWT was establishedin order to determine the exercise capacity in patients with pulmonary failure, and since then it has been used worldwide in different fields including obesity, cystic fibrosis, interstitial lung disease, chronic obstructive pulmonary disease, cardiovascular diseases, and neurologic disorders $[15,18,19]$.

There are some reports in the literature regarding the lack of standardization in both pediatric and adult population, however $6 \mathrm{mWT}$ is a commonly used and worldwide accepted test, and it has been used in many patients with functional results $[20,21]$. $6 \mathrm{mWT}$ primarily developed for evaluating patients for pulmonary function but also used for very variable assessments like walking speed and endurance with spinal cord injury patients [15], to show oxygen up-take of patients with claudication [17], for prognostic purpose of cardiovascular diseases [22].

Nasal aerodynamics is important for tissue oxygenation during exercise. Reducing the nasal airway resistance provides improvement of the exercise capacity. To determine the exercise capacity in nasal obstruction, Boas et al. [23] used 6mWT in healthy individuals without any pulmonary diseases to compare mouth breathers and nose breathers, and the results indicated that mouth breather subjects had lower scores compared to nose breathers. In 9 healthy subjects, Tong et al. [24] showed that nasal nostril dilatators were capable to increase perceived magnitude of breathing effort when compared to oronasal breathing and the control groups. Morton et al. [25] studied on 20 healthy adults to reveal maximal ventilation and maximal oxygen consumption during physical activity. Three groups' (consisted of nose-breathing, mouth-breathing, nose+mouth breathing subjects) comparative results showed that nose breathing group has decreased oxygen consumption and ventilation than other groups.

In the review of the literature there are different results including blood pressure difference following exercise tests. However there is constant results for decreased blood pressure levels for each study usually it is observed that if systolic pressure decreases, diastolic pressure decrease as well and these report related to dietary supplements which are prone to effect the blood pressure $[26,27]$. Without a medication there is no significant difference could be expected in blood pressure as contrast to our result. And the major reason for our finding regarding diastolic blood increase might be explained the low number of patients would show the minor changes over influence effect on our results.

Borghi-Silva et al. [28] used 6 MWT for reveal the response of physical training on exercise capacity and they found statistically significant increase of heart rate following exercise on 6th and 12th week compared to baseline. Total distance was also increased in their study and heart rate seems to correlate with increased exercise capacity in a constant timeframe as similar to our study.

However these results belong to considerably early postoperative period, in most studies there are no significant differences found between early (4-6-8 weeks) and late (3-6 months) follow-up period regarding pulmonary function results $[29,30]$. In our study we aimed to discuss primarily to see the effect of pulmonary function improvement following early stage of septoplasty in healthy subjects and these findings give promising results to researchers for further long-term investigations.

This result suggests that widening of the nasal cavity has a positive impact on exercise capacity even in the healthy individuals without any pulmonary obstruction. In our study, we showed an increase in the total tour count postoperatively. Subjective evaluation of the patients' NOSE and SNOT scores significantly reduced following surgery as well. However there is no significant correlation with subjective and objective data analysis. This result leads us to think that pulmonary function improvement is not directly exhibit patient's perspective but surgical fixation of the obstruction. Since all patients are selected from markedly deviated (deflection-impaction) our hypostasis is physical examination seems to be more important factor. The differences of $6 \mathrm{mWT}$ before and after surgery in our study may be encouraging for nasal septal surgery, particularly in the professionally active sportsmen.

In conclusion, in case of a markedly deviated nasal septum, 
septoplasty improves extrathoracic parameters of the spirometry. $6 \mathrm{mWT}$ is also a good test to evaluate the patients' total walking distance without distorting physiologic parameters such as heart rate, oxygen saturation and Borg scale. New studies are needed to determine the effect of septoplasty in patients with restricted pulmonary capacity.

\section{CONFLICT OF INTEREST}

No potential conflict of interest relevant to this article was reported.

\section{REFERENCES}

1. Stewart MG, Smith TL, Weaver EM, Witsell DL, Yueh B, Hannley MT, et al. Outcomes after nasal septoplasty: results from the nasal obstruction septoplasty effectiveness (NOSE) study. Otolaryngol Head Neck Surg. 2004 Mar;130(3):283-90.

2. Hopkins C, Gillett S, Slack R, Lund VJ, Browne JP. Psychometric validity of the 22-item sinonasal outcome test. Clin Otolaryngol. 2009 Oct;34(5):447-54.

3. Buckland JR, Thomas S, Harries PG. Can the sino-nasal outcome test (SNOT-22) be used as a reliable outcome measure for successful septal surgery? Clin OtolaryngolAllied Sci. 2003 Feb;28(1):43-7.

4. American Thoracic Society. Standardization of spirometry, 1994 update.Am J Respir Crit Care Med. 1995 Sep;152(3):1107-36.

5. Karaman M,Tek A, Tuncel A, Erdem Habesoglu T. Evaluation of patients with septal deviation using respiratory function tests before and after septoplasty. Kulak Burun Bogaz Bas Boyun Cerrahi Derg. 2011;19(1):1-5.

6. Grippi MA, Tino G. Pulmonary function testing. In: Fishman AP, Elias JA, Fishman JA, Grippi MA, Senior RM, Pack AI, editors. Fishman's pulmonary diseases and disorders. 4th ed. New York: McGraw Hill; 2008. p. 567-610.

7. Ruppel GL. Manual of pulmonary function testing. 9th ed. St. Louis (MO): Mosby Elsevier; 2009. Chapter 1. Indications for pulmonary function testing; 1-29.

8. Fuso L, Cisternino L, Di Napoli A, Di Cosmo V, Tramaglino LM, Basso S, et al. Role of spirometric and arterial gas data in predicting pulmonary complications after abdominal surgery. Respir Med. 2000 Dec;94(12):1171-6.

9. Smetana GW. Preoperative pulmonary evaluation. N Engl J Med. 1999 Mar;340(12):937-44.

10. Pellegrino R, Viegi G, Brusasco V, Crapo RO, Burgos F, Casaburi R, et al. Interpretative strategies for lung function tests. Eur Respir J. 2005 Nov;26(5):948-68.

11. Rotman HH, Liss HP, Weg JG. Diagnosis of upper airway obstruction by pulmonary function testing. Chest. 1975 Dec;68(6):796-9.

12. Morinaga M, Nakata S, Yasuma F, Noda A, Yagi H, Tagaya M, et al. Pharyngeal morphology: a determinant of successful nasal surgery for sleep apnea. Laryngoscope. 2009 May;119(5):1011-6.

13. Dogan OT, Yildirim A, Epozturk K, Dogan M. Another advantage of nasal septal suturing: pulmonary function unaffected. B-ENT. 2012;8(1):21-4.

14. Niedzielska G, Kotowski M, Niedzielski A. Assessment of pulmo- nary function and nasal flow in children with adenoid hypertrophy. Int J Pediatr Otorhinolaryngol. 2008 Mar;72(3):333-5.

15. Hayes HB, Jayaraman A, Herrmann M, Mitchell GS, Rymer WZ, Trumbower RD. Daily intermittent hypoxia enhances walking after chronic spinal cord injury: a randomized trial. Neurology. 2014 Jan;82(2):104-13.

16. Narotzki B, Reznick AZ, Navot-Mintzer D, Dagan B, Levy Y. Green tea and vitamin $\mathrm{E}$ enhance exercise-induced benefits in body composition, glucose homeostasis, and antioxidant status in elderly men and women. J Am Coll Nutr. 2013;32(1):31-40.

17. Gardner AW, Ritti-Dias RM, Stoner JA, Montgomery PS, Khurana A, Blevins SM. Oxygen uptake before and after the onset of claudication during a 6-minute walk test. JVasc Surg. 2011 Nov;54(5):1366-73.

18. Butland RJ, Pang J, Gross ER, Woodcock AA, Geddes DM. Two-, six, and 12-minute walking tests in respiratory disease. Br Med J (Clin Res Ed). 1982 May;284(6329):1607-8.

19. Poulain M, Durand F, Palomba B, Ceugniet F, Desplan J,Varray A, et al. 6-minute walk testing is more sensitive than maximal incremental cycle testing for detecting oxygen desaturation in patients with COPD. Chest. 2003 May;123(5):1401-7.

20. Pereira FM, Ribeiro MA, Ribeiro AF, Toro AA, Hessel G, Ribeiro JD. Functional performance on the six-minute walk test in patients with cystic fibrosis. J Bras Pneumol. 2011 Nov-Dec;37(6):735-44.

21. Noonan V, Dean E. Submaximal exercise testing: clinical application and interpretation. Phys Ther. 2000 Aug;80(8):782-807.

22. Casillas JM, Hannequin A, Besson D, Benaïm S, Krawcow C, Laurent Y, et al. Walking tests during the exercise training: specific use for the cardiac rehabilitation. Ann Phys Rehabil Med. 2013 Oct;56(7-8): 561-75.

23. Boas AP, Marson FA, Ribeiro MA, Sakano E, Conti PB, Toro AD, et al. Walk test and school performance in mouth-breathing children. Braz J Otorhinolaryngol. 2013 Mar-Apr;79(2):212-8.

24. Tong TK, Fu FH, Chow BC. Nostril dilatation increases capacity to sustain moderate exercise under nasal breathing condition. J Sports Med Phys Fitness. 2001 Dec;41(4):470-8.

25. Morton AR, King K, Papalia S, Goodman C, Turley KR, Wilmore JH. Comparison of maximal oxygen consumption with oral and nasal breathing. Aust J Sci Med Sport. 1995 Sep;27(3):51-5.

26. Shepherd AI, Wilkerson DP, Dobson L, Kelly J, Winyard PG, Jones $\mathrm{AM}$, et al.The effect of dietary nitrate supplementation on the oxygen cost of cycling, walking performance and resting blood pressure in individuals with chronic obstructive pulmonary disease: A double blind placebo controlled, randomised control trial. Nitric Oxide. 2015 Aug;48:31-7.

27. Berry MJ, Justus NW, Hauser JI, Case AH, Helms CC, Basu S, et al. Dietary nitrate supplementation improves exercise performance and decreases blood pressure in COPD patients. Nitric Oxide. 2015 Aug; 48:22-30.

28. Borghi-Silva A, Mendes RG, Trimer R, Oliveira CR, Fregonezi GA, Resqueti VR, et al. Potential effect of 6 versus 12-weeks of physical training on cardiac autonomic function and exercise capacity in chronic obstructive pulmonary disease. Eur J Phys Rehabil Med. 2015 Apr;51(2):211-21.

29. Baguley CJ, Stow NW, Weitzel EK, Douglas RG. Silastic splints reduce middle meatal adhesions after endoscopic sinus surgery. Am J Rhinol Allergy. 2012 Sep-Oct;26(5):414-7.

30. Garzaro M, Pezzoli M, Pecorari G, LandolfoV, Defilippi S, Giordano C. Radiofrequency inferior turbinate reduction: an evaluation of olfactory and respiratory function. Otolaryngol Head Neck Surg. 2010 Sep;143(3):348-52. 